Research article

\title{
Patients with early rheumatoid arthritis exhibit elevated autoantibody titers against mildly oxidized low-density lipoprotein and exhibit decreased activity of the lipoprotein-associated phospholipase $\mathbf{A}_{2}$
}

\author{
Evangelia S Lourida1, Athanasios N Georgiadis², Eleni C Papavasiliou1, \\ Athanasios I Papathanasiou², Alexandros A Drosos ${ }^{2}$ and Alexandros D Tselepis ${ }^{1}$
}

1Department of Chemistry, Laboratory of Biochemistry, University of loannina, 45110 loannina, Greece

${ }^{2}$ Department of Internal Medicine, Medical School, University of loannina, 45110 loannina, Greece

Corresponding author: Alexandros D Tselepis, atselep@uoi.gr

Received: 20 Oct 2006 Revisions requested: 4 Dec 2006 Revisions received: 22 Jan 2007 Accepted: 27 Feb 2007 Published: 27 Feb 2007

Arthritis Research \& Therapy 2007, 9:R19 (doi:10.1186/ar2129)

This article is online at: http://arthritis-research.com/content/9/1/R19

(c) 2007 Lourida et al., licensee BioMed Central Ltd.

This is an open access article distributed under the terms of the Creative Commons Attribution License (http://creativecommons.org/licenses/by/2.0), which permits unrestricted use, distribution, and reproduction in any medium, provided the original work is properly cited.

\begin{abstract}
Rheumatoid arthritis is a chronic inflammatory disease, associated with an excess of cardiovascular morbidity and mortality due to accelerated atherosclerosis. Oxidized lowdensity lipoprotein (oxLDL), the antibodies against oxLDL and the lipoprotein-associated phospholipase $A_{2}\left(L p-P L A_{2}\right)$ may play important roles in inflammation and atherosclerosis. We investigated the plasma levels of oxLDL and Lp-PLA $A_{2}$ activity as well as the autoantibody titers against mildly oxLDL in patients with early rheumatoid arthritis (ERA). The long-term effects of immunointervention on these parameters in patients with active disease were also determined. Fifty-eight ERA patients who met the American College of Rheumatology criteria were included in the study. Patients were treated with methotrexate and prednisone. Sixty-three apparently healthy volunteers also participated in the study and served as controls. Three different types of mildly oxLDL were prepared at the end of the lag, propagation and decomposition phases of oxidation. The serum autoantibody titers of the IgG type against all types of oxLDL were determined by an ELISA method. The plasma levels of oxLDL and the Lp-PLA ${ }_{2}$ activity were determined by an ELISA
\end{abstract}

method and by the trichloroacetic acid precipitation procedure, respectively. At baseline, ERA patients exhibited elevated autoantibody titers against all types of mildly oxLDL as well as low activity of the total plasma Lp-PLA ${ }_{2}$ and the $L p-P L A_{2}$ associated with the high-density lipoprotein, compared with controls. Multivariate regression analysis showed that the elevated autoantibody titers towards oxLDL at the end of the decomposition phase of oxidation and the low plasma Lp-PLA ${ }_{2}$ activity are independently associated with ERA. After immunointervention autoantibody titers against all types of oxLDL were decreased in parallel to the increase in high-density lipoprotein-cholesterol and high-density lipoprotein-Lp-PLA activity. We conclude that elevated autoantibody titers against oxLDL at the end of the decomposition phase of oxidation and low plasma Lp-PLA ${ }_{2}$ activity are feature characteristics of patients with ERA, suggesting an important role of these parameters in the pathophysiology of ERA as well as in the accelerated atherosclerosis observed in these patients.

\section{Introduction}

Rheumatoid arthritis is a chronic inflammatory condition of unknown etiology affecting primarily the synovium, leading to joint damage and bone destruction [1]. Rheumatoid arthritis causes significant morbidity as a result of synovial inflammation, joint destruction and associated disability. Several investigators have reported an excess of cardiovascular morbidity and mortality among rheumatoid arthritis patients. In active

Apo A-I = apolipoprotein A-I; Apo B = apolipoprotein B-100; CRP = C-reactive protein; DMARDs = disease-modifying antirheumatic drugs; ELISA $=$ enzyme-linked immunosorbent assay; ERA = early rheumatoid arthritis; $\mathrm{HDL}=$ high-density lipoprotein; $\mathrm{Lp}(\mathrm{a})=$ lipoprotein (a); Lp-PLA ${ }_{2}=$ lipoprotein-associated phospholipase $A_{2} ; \mathrm{HDL}-\mathrm{Lp}-\mathrm{PLA} \mathrm{A}_{2}=$ high-density lipoprotein-associated phospholipase $A_{2} ; \mathrm{IL}=$ interleukin; $L D L=$ low-density lipopro-

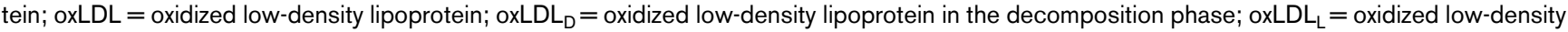
lipoprotein in the lag phase; $o x L D L_{P}=$ oxidized low-density lipoprotein in the propagation phase. 
rheumatoid arthritis, the majority of cardiovascular deaths result from accelerated atherosclerosis [2-5].

Oxidative modification of low-density lipoprotein (LDL) is an important event in the development and progression of atherosclerosis. Oxidized low-density lipoprotein (oxLDL) is present in atherosclerotic lesions of humans and animal models, and promotes atherosclerosis by several mechanisms [6-9]. oxLDL has been detected in patients with systemic lupus erythematosus and the antiphospholipid syndrome and also in the synovium and synovial fluids of rheumatoid arthritis patients $[10,11]$.

During LDL oxidation both the lipids and apolipoprotein B-100 (Apo B) undergo a variety of chemical changes via radicalmediated reactions as well as modifications by chemically active products formed on oxLDL particles [12]. An important biochemical change that takes place during LDL oxidation is the hydrolysis of its content in oxidized phospholipids and the production of lysophosphatidylcholine. This reaction is catalyzed by the lipoprotein-associated phospholipase $A_{2}$ (Lp$P L A_{2}$ ), also known as platelet-activating factor acetylhydrolase [13]. Lp-PLA $\mathrm{A}_{2}$ exhibits a $\mathrm{Ca}^{2+-i n d e p e n d e n t ~ p h o s p h o l i p a s e ~} \mathrm{~A}_{2}$ activity and preferentially hydrolyses biologically active phospholipids containing short acyl groups at the $s n-2$ position, such as platelet-activating factor and oxidized phospholipids [13]; this enzyme therefore plays important roles in inflammatory reactions and atherosclerosis [14]. In human plasma Lp$\mathrm{PLA}_{2}$ is associated mainly with LDL, whereas a small proportion of circulating enzyme activity is also associated with highdensity lipoprotein (HDL) $[13,15]$. Data from large Caucasian population studies have demonstrated an independent association between plasma Lp-PLA ${ }_{2}$ (which represents mainly the LDL-associated $L p-P L A_{2}$ ) and the risk of future cardiovascular events $[16,17]$. In contrast to the total plasma enzyme, several lines of evidence suggest that HDL-associated Lp-PLA $A_{2}$ activity (HDL-Lp-PLA $A_{2}$ ), although at low levels in plasma, may contribute to the antiatherogenic effects of this lipoprotein [13].

oxLDL is immunogenic and some of its constituents (oxidized phospholipids, aldehydes and lysophosphatidylcholine) play important roles in the oxLDL antigenicity, participating in the formation of several different epitopes. These epitopes are recognized by specific autoantibodies, which are present in serum of healthy individuals as well as in various pathologic conditions [18]. We recently showed, using various types of mildly oxLDL as antigens, that the extent of LDL oxidation and the levels of LDL-associated Lp-PLA ${ }_{2}$ activity significantly influence the antibody titers against oxLDL in patients with stable angina $[19,20]$. Furthermore, we recently showed that the LDL-associated Lp-PLA ${ }_{2}$ plays an important role in modulating the immune responses against various types of mildly oxLDL observed after an acute coronary syndrome without persistent elevation of the ST segment [21].
The aim of the present study was to investigate the plasma levels of oxLDL and Lp-PLA $A_{2}$ activity as well as the autoantibody titers against various types of mildly oxidized LDL in patients with early rheumatoid arthritis (ERA). The long-term effects of immunointervention on these parameters in patients with active disease were also determined.

\section{Materials and methods Patients}

Fifty-eight consecutive patients with ERA (14 men and 44 women) who met the American College of Rheumatology 1987 criteria for rheumatoid arthritis [22] and 63 apparently healthy nonsmoking volunteers (controls) were investigated. ERA patients were $>18$ years of age and had early inflammatory disease (disease duration $<12$ months) without prior use of disease-modifying antirheumatic drugs (DMARDs) and/or corticosteroids. All patients were recruited from the outpatient rheumatology clinic of the University Hospital of Ioannina, Greece. Details on the eligibility criteria for inclusion or exclusion from the study were reported in our previously published prospective, controlled study [23].

ERA patients were treated with methotrexate $(0.2 \mathrm{mg} / \mathrm{kg} /$ week), and prednisone $(7.5 \mathrm{mg} /$ day $)$. The dose of methotrexate remained stable during the study, while the dose of prednisone was tapered to $5 \mathrm{mg} /$ day according to the patients' clinical response. Disease activity was assessed by measuring the disease activity score for 28 joint indices [24], while the clinical response was evaluated according to the American College of Rheumatology 50\% response criteria [25]. All patients were followed up every month for the first 3 months, and every 3 months thereafter. During the follow-up period, a questionnaire concerning changes in dietary habits was carefully completed by all patients. The body weight was also measured appropriately in each visit. Overnight fasting blood samples were obtained at baseline and after 12 months follow-up from both the ERA patients and the control group. The Ethics Committee of the University Hospital of loannina approved the study and written informed consent was obtained from each patient and each healthy volunteer.

\section{Measurement of autoantibody titers against oxidized low-density lipoprotein}

LDL (density $=1.019-1.063 \mathrm{~g} / \mathrm{ml}$ ) was isolated by sequential ultracentrifugation from pooled fresh plasma [26]. LDL, at a final concentration of $100 \mu \mathrm{g}$ protein $/ \mathrm{ml}$, was oxidized in the presence of $5 \mu \mathrm{M} \mathrm{CuSO}_{4}$ for up to 3 hours at $37^{\circ} \mathrm{C}$ under continuous monitoring of the increase in the absorbance at 234 $\mathrm{nm}$, as we recently described $[19,20]$. Oxidation of LDL was terminated by the addition of $0.01 \%$ ethylenediamine tetraacetic acid either at the end of the lag phase (oxLDL $L_{L}$ ), at the end of the propagation phase (oxLDL $L_{P}$ ), or during the decomposition phase $\left(o x L D L_{D}\right), 3$ hours after the onset of oxidation $[19,20]$. The serum autoantibody titers of the lgG type against all types of oxLDL were determined by an ELISA method, as 
we recently described $[19,20]$. The results were expressed as the ratio of antibody binding to various types of oxLDL versus LDL $[19,20]$.

\section{Determination of lipoprotein-associated phospholipase $A_{2}$ activity}

The Lp-PLA ${ }_{2}$ activity in plasma and in HDL-rich plasma, after the sedimentation of all Apo B-containing lipoproteins with dextran sulfate-magnesium chloride (HDL-Lp-PLA $A_{2}$ ), was measured by the trichloroacetic acid precipitation procedure, using 1-O-hexadecyl-2- [3H-acetyl]-sn-glycero-3-phosphocholine as a substrate at a final concentration of $100 \mu \mathrm{mol} / \mathrm{l}$. The reaction was performed for $10 \mathrm{~min}$ at $37^{\circ} \mathrm{C}$ and the $\mathrm{Lp}$ $\mathrm{PLA}_{2}$ activity was expressed as nanomoles of 1-O-hexadecyl2-acetyl-sn-glycero-3-phosphocholine degraded per minute per milliliter of plasma $[20,27,28]$. The minimum detection limit of the assay is $0.8 \mathrm{nmol} / \mathrm{min} / \mathrm{ml}$ plasma, whereas the intraassay and inter-assay coefficients of variation are $3.3-4.2 \%$ and $7.1-8.0 \%$, respectively.

\section{Analytical methods}

Serum lipids were determined after 12 hours overnight fast. Total cholesterol, triglycerides and HDL-cholesterol levels were determined on the Olympus AU560 Clinical Chemistry analyzer (Hamburg, Germany) as previously described [28]. LDL-cholesterol was estimated by calculation, using the Friedewald formula [29]. Serum Apo B and apolipoprotein A-I (Apo A-I) levels were measured by immunonephelometry with the aid of a Behring Nephelometer BN100 and reagents (antibodies and calibrators) from Behring Diagnostics $\mathrm{GmbH}$ (Liederbach, Germany). Serum lipoprotein (a) (Lp(a)) levels were determined by an enzyme immunoassay method (Macra Lp(a); Terumo Medical Corporation Diagnostic Division, Elkton, MD, USA) [27]. C-reactive protein (CRP) and IgM rheumatoid factor were measured by nephelometry. The erythrocyte sedimentation rate was measured by the modified Westergren method.

\section{Statistical analysis}

Data were expressed as the mean \pm standard deviation. Statistical analysis was performed using the paired Student's $t$ test for comparisons between baseline and post-treatment values, while one-way analysis of variance followed by the least significant difference post hoc test was used for comparisons between individual groups. Comparison between baseline and post-treatment CRP levels was performed using the KruskalWallis test while CRP levels between individual groups were compared using the Mann-Whitney $U$ test. Correlation between variables was examined using the Pearson's correlation coefficient. We used multivariate logistic regression analysis to calculate the adjusted odd ratios and 95\% confidence intervals for the two study groups.

Matched groups were constructed taking into account the significant factors as derived from the univariate logistic regression analysis. The model selection used the backward stepwise method (likelihood ratios), and variables at a $P$ value less than 0.05 were retained in the model as independent variables. The variables included in the univariate analysis were the following: age, total cholesterol, LDL-cholesterol, HDLcholesterol, triglycerides, Apo B, Apo A-I, autoantibody titers against oxLDL $L_{L}$, oxLDL $L_{P}$ and $\operatorname{oxLDL}_{D}$, plasma $L p-P L A_{2}$ activity, HDL-Lp-PLA $A_{2}$ activity (continuous variables) and female gender (dichotomous variable). All statistical analyses were carried out with SPSS 12.0 (SPSS Inc., Chicago, IL, USA). In all cases, $P<0.05$ was considered statistically significant.

\section{Results \\ Patients' characteristics and lipid profile}

Fifty-eight patients with ERA and 63 apparently healthy volunteers participated in the study. The clinical and biochemical characteristics of the study population are presented in Table 1. There was no observed difference in sex distribution, age and body mass index between ERA patients and controls. As expected, ERA patients exhibited increased levels of the inflammatory markers CRP and erythrocyte sedimentation rate and had a high disease activity score as measured by the disease activity score for 28 joint indices (Table 1). In addition, ERA patients exhibited a mild dyslipidemia characterized by an increase in the serum levels of total cholesterol, LDL-cholesterol, triglycerides and Apo $B$ as well as by a decrease in the serum levels of HDL-cholesterol and Apo A-I compared with controls. No difference in the serum $L p(a)$ levels was observed between the two study groups.

One year of therapy with DMARDs in ERA patients resulted in a significant decrease of the inflammatory markers CRP and the erythrocyte sedimentation rate as well as in the reduction of the disease activity score for 28 joint indices (Table 1). In addition, one year of therapy with DMARDs resulted in a significant increase in the serum levels of total cholesterol, HDLcholesterol and Apo A-I compared with the respective baseline values (Table 1). It should be noted that no female patient was receiving hormone replacement therapy either at baseline or during the follow-up period.

\section{Lipoprotein-associated phospholipase $A_{2}$ activity}

At baseline, ERA patients exhibited a significantly lower activity of total plasma Lp-PLA 2 and of HDL-Lp-PLA ${ }_{2}$, compared with controls (Table 1). One year of therapy with DMARDs did not influence the total plasma $\mathrm{Lp}-\mathrm{PLA}_{2}$ but it significantly increased the HDL-Lp-PLA 2 activity (Table 1).

\section{Autoantibody titers against oxidized low-density lipoprotein}

Three types of mildly oxLDL were prepared and used as antigens: $\operatorname{oxLDL}_{L}$ at the end of the lag phase, $\operatorname{oxLDL}_{P}$ at the end of the propagation phase and $\operatorname{oxLDL}_{\mathrm{D}}$ at the decomposition phase, 3 hours after the onset of oxidation. As shown in Table 2 , ERA patients exhibited higher autoantibody titers against all types of oxLDL at baseline compared with controls. Impor- 
Table 1

Clinical characteristics and lipid profile of early rheumatoid arthritis patients and controls

\begin{tabular}{|c|c|c|c|}
\hline & \multirow[t]{2}{*}{ Controls $(n=63)$} & \multicolumn{2}{|c|}{ Early rheumatoid arthritis patients } \\
\hline & & Baseline $(n=58)$ & Post-treatment $(n=56)$ \\
\hline Sex (males/females) & $20 / 43$ & $14 / 44$ & $13 / 43$ \\
\hline Age (years) & $58.4 \pm 17.7$ & $53.6 \pm 15.3$ & $54.7 \pm 14.8$ \\
\hline Body mass index $\left(\mathrm{kg} / \mathrm{m}^{2}\right)$ & $25.8 \pm 6.5$ & $25.5 \pm 3.3$ & $25.8 \pm 3.1$ \\
\hline IgM rheumatoid factor $(+/-)$ & $0 / 0$ & $45 / 13$ & $44 / 13$ \\
\hline C-reactive protein (mg/dl) & $3(1-5)$ & $22(7-104)$ & $3(1-5)^{\ddagger}$ \\
\hline Disease activity score for 28 joint indices & - & $5.8 \pm 0.9$ & $2.7 \pm 1.0^{\ddagger}$ \\
\hline Erythrocyte sedimentation rate $(\mathrm{mm} / \mathrm{h})$ & $5.2 \pm 3.1$ & $48.0 \pm 19.7$ & $14.6 \pm 8.7^{\ddagger}$ \\
\hline Total cholesterol (mg/dl) & $190.4 \pm 33.9$ & $216.5 \pm 50.3^{*}$ & $228.1 \pm 42.1^{\star \star}$ \\
\hline Low-density lipoprotein-cholesterol (mg/dl) & $126.5 \pm 31.3$ & $141.6 \pm 42.3^{*}$ & $140.4 \pm 32.4$ \\
\hline High-density lipoprotein-cholesterol (mg/dl) & $51.1 \pm 7.4$ & $47.5 \pm 11.8^{\dagger}$ & $60.7 \pm 13.4^{\ddagger}$ \\
\hline Triglycerides (mg/dl) & $97.1 \pm 28.3$ & $133.0 \pm 58.2^{*}$ & $131.5 \pm 56.1$ \\
\hline Apolipoprotein B-100 (mg/dl) & $93 \pm 19$ & $103 \pm 28^{*}$ & $105 \pm 30$ \\
\hline Apolipoprotein A-I (mg/dl) & $144 \pm 23$ & $127 \pm 27^{\dagger}$ & $152 \pm 22^{\ddagger}$ \\
\hline Lipoprotein (a) (mg/dl) & $10.6(0.8-28.0)$ & $11.2(2.5-39.7)$ & $8.6(2.5-38.1)$ \\
\hline Plasma lipoprotein phospholipase $A_{2}$ activity $(\mathrm{nmol} / \mathrm{ml} / \mathrm{min}$ ) & $58.6 \pm 14.0$ & $47.1 \pm 19.3^{\dagger}$ & $45.7 \pm 14.6$ \\
\hline High-density lipoprotein-associated lipoprotein phospholipase $A_{2}$ activity $(\mathrm{nmol} / \mathrm{ml} / \mathrm{min}$ ) & $3.4 \pm 1.3$ & $2.7 \pm 1.0^{*}$ & $3.6 \pm 1.3^{\ddagger}$ \\
\hline
\end{tabular}

Data presented as the mean \pm standard deviation or as the median (range). ${ }^{\star} P<0.001$ and ${ }^{\dagger} P<0.0001$ compared with controls, ${ }^{\ddagger} P<0.001$ and ${ }^{\star \star} P<0.01$ compared with baseline values.

tantly, the autoantibody titers against oxLDL $L_{P}$ and oxLDL $L_{D}$ were inversely correlated with serum HDL-cholesterol levels (Figure 1). In addition, autoantibody titers against $\operatorname{oxLDL}_{D}$ were inversely correlated with HDL-Lp-PLA 2 activity (Figure 1). One year of therapy with DMARDs resulted in a significant decrease in autoantibody titers against all types of oxLDL in ERA patients compared with the respective baseline values (Table 2).

\section{Association of autoantibody titers against oxidized LDL and plasma lipoprotein-associated phospholipase $A_{2}$ with early rheumatoid arthritis}

We initially performed univariate analysis using the lipid parameters that were significant different between ERA patients and controls, the antibody titers against the various types of oxLDL and the Lp-PLA $A_{2}$ activity, in order to evaluate their relationships with the presence of ERA. The results of this analysis showed that only autoantibody titers against all types of oxLDL as well as the low plasma Lp-PLA ${ }_{2}$ activity are associated with ERA (Table 3). To further identify whether these parameters could independently be associated with ERA, multivariate logistic regression analysis was performed, taking into account all statistically significant factors as they derived from univariate analysis. In the multivariate analysis model we therefore included the autoantibody titers against oxLDL $L_{L}$, oxLDL $L_{P}$ and $\operatorname{oxLDL}_{D}$, and the plasma Lp-PLA 2 activity as defined from univariate analysis. In this analysis ERA showed significant associations only with autoantibody titers against $\mathrm{oxLDL}_{\mathrm{D}}$ and plasma LpPLA $_{2}$ activity (Table 4).

\section{Discussion}

The present study shows for the first time that ERA patients exhibit low plasma Lp-PLA ${ }_{2}$ activity and elevated autoantibody titers against mildly oxidized types of $L D L$ (oxLDL $L_{L}, o x L D L_{p}$ and $\operatorname{oxLDL}_{D}$ ), compared with controls. The low Lp-PLA $A_{2}$ activity is in accordance with previously published data by our group, indicating that patients with active juvenile rheumatoid arthritis presented with lower plasma Lp-PLA $A_{2}$ activity compared with those with inactive disease or to controls [30]. The present study further shows that the low Lp-PLA $A_{2}$ activity is independently associated with ERA. It is well established that the main cellular source of the plasma form of $L p-P L A_{2}$ is monocytes, which secrete this enzyme during their differentiation into macrophages [31]. The cellular expression of plasma Lp-PLA $A_{2}$ is regulated by various factors, including the differentiation state of the cell and the degree of activation by proinflammatory mediators $[13,32]$. Most of the proinflammatory mediators (lipopolysaccharide, tumor necrosis factor alpha, IL-1, IL-8, and interferon gamma) inhibit Lp-PLA $A_{2}$ expression by macrophages in vitro [13]. The reduction in plasma Lp-PLA $A_{2}$ activity found in ERA patients could therefore be attributed to the inflammation-induced decrease in the enzyme expression. According to our previously published results, however, another important determinant of the plasma Lp-PLA $A_{2}$ activity 
Table 2

Autoantibody titers against various types of oxidatively modified low-density lipoprotein (oxLDL) in early rheumatoid arthritis patients and controls

\begin{tabular}{llll}
\hline Antigen & Controls $(n=63)$ & \multicolumn{2}{l}{ Early rheumatoid arthritis patients } \\
\cline { 3 - 3 } & & Baseline $(n=58)$ & Post-treatment $(n=56)$ \\
\hline oxLDL in the lag phase & $0.919 \pm 0.271$ & $1.131 \pm 0.229^{\star}$ & $0.872 \pm 0.198^{\dagger}$ \\
oxLDL in the propagation phase & $0.962 \pm 0.289$ & $1.223 \pm 0.278^{\star}$ & $1.045 \pm 0.300^{\ddagger}$ \\
oxLDL in the decomposition phase & $0.985 \pm 0.376$ & $1.375 \pm 0.327^{\star}$ & $1.144 \pm 0.247^{\star \star}$
\end{tabular}

Data presented as the mean \pm standard deviation. ${ }^{\star} P<0.0001$ compared with controls, ${ }^{\dagger} P<0.001,{ }^{\ddagger} P<0.01$ and ${ }^{* *} P<0.05$ compared with baseline values.

is the plasma LDL level $[27,28]$. Indeed, $L p-P L A_{2}$ in plasma is mainly bound on LDL particles, whereas a small proportion is associated with HDL [13]. We may consequently suggest that the low levels of enzyme activity in the plasma of ERA patients at baseline could be the combined effect of the inflammationinduced reduction of enzyme secretion from macrophages and the expected increase in plasma enzyme levels due to the elevation of LDL-cholesterol in plasma of ERA patients.
The dependence of the plasma Lp-PLA ${ }_{2}$ levels from the LDLcholesterol levels could also explain our results showing that therapy with DMARDs did not affect either the plasma LDLcholesterol levels or the plasma Lp-PLA ${ }_{2}$ activity. A factor that could also influence the plasma Lp-PLA $A_{2}$ levels in ERA patients is $L p(a)$. Indeed, we [33] and others [34] have previously shown that $L p(a)$ contains several-fold greater Lp-PLA $A_{2}$ activity

Figure 1

(a)

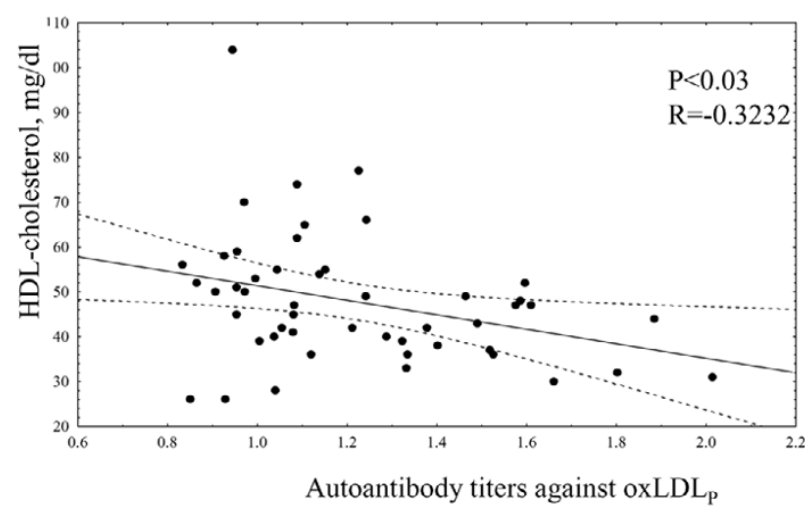

(b)

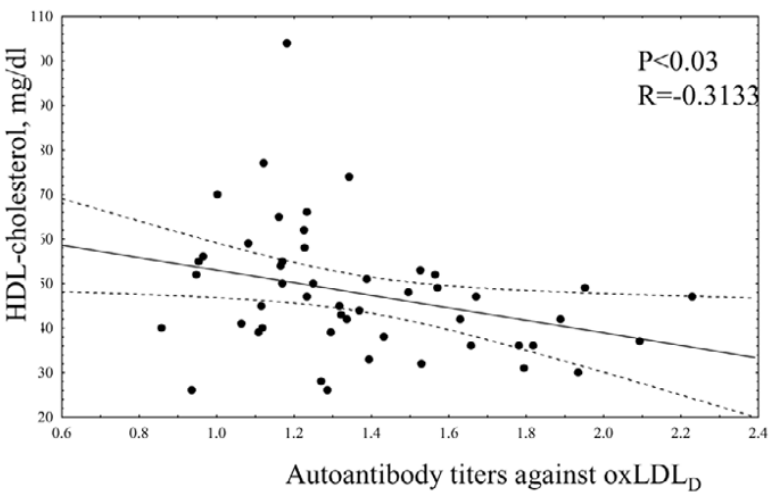

(c)

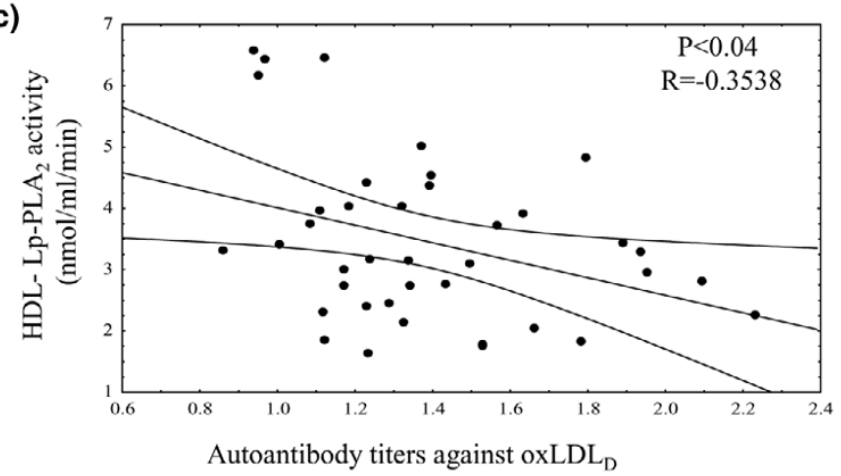

Correlation between serum levels of high-density lipoprotein-cholesterol and autoantibody titers against oxidized low-density lipoprotein. Correlation between serum levels of high-density lipoprotein (HDL)-cholesterol and autoantibody titers against (a) oxidized low-density lipoprotein in the propagation phase (oxLDL $L_{P}$ ) and (b) oxidized low-density lipoprotein in the decomposition phase (oxLDL $L_{D}$ ) in early rheumatoid arthritis patients at baseline. (c) Correlation between HDL-associated lipoprotein-associated phospholipase $A_{2}\left(H D L-L p-P L A_{2}\right)$ activity and autoantibody titers against oxLDL $L_{D}$ in early rheumatoid arthritis patients at baseline. 
Table 3

Univariate logistic regression analysis of factors associated with the presence of early rheumatoid arthritis

\begin{tabular}{|c|c|c|c|}
\hline & Odds ratio & $95 \%$ confidence interval & $P$ value \\
\hline Age & 1.009 & $0.982-1.036$ & Not significant \\
\hline Female gender & 1.014 & $0.965-1.123$ & Not significant \\
\hline Total-cholesterol & 0.998 & $0.990-1.006$ & Not significant \\
\hline Low-density lipoprotein-cholesterol & 0.960 & $0.991-1.010$ & Not significant \\
\hline High-density lipoprotein-cholesterol & 0.969 & $0.931-1.008$ & Not significant \\
\hline Triglycerides & 0.998 & $0.991-1.006$ & Not significant \\
\hline Apolipoprotein B-100 & 1.012 & $0.934-1.134$ & Not significant \\
\hline Apolipoprotein A-I & 0.985 & $0.876-1.078$ & Not significant \\
\hline Antibodies against oxidized low-density lipoprotein in the lag phase & 0.027 & $0.004-0.177$ & 0.000 \\
\hline Antibodies against oxidized low-density lipoprotein in the propagation phase & 0.029 & $0.005-0.171$ & 0.000 \\
\hline Antibodies against oxidized low-density lipoprotein in the decomposition phase & 0.034 & $0.008-0.152$ & 0.000 \\
\hline Plasma lipoprotein phospholipase $\mathrm{A}_{2}$ activity & 1.038 & $1.012-1.066$ & 0.004 \\
\hline High-density lipoprotein-associated lipoprotein phospholipase $A_{2}$ activity & 1.021 & $0.897-1.245$ & Not significant \\
\hline
\end{tabular}

compared with LDL when assayed at equimolar protein concentrations. Importantly, recent results have provided evidence that the $\mathrm{Lp}(\mathrm{a})$-associated $\mathrm{Lp}-\mathrm{PLA}_{2}$ may play an important role by degrading oxidized phospholipids that are preferentially sequestered on $\operatorname{Lp}(\mathrm{a})$ [35]. It is unlikely, however, that the $\mathrm{Lp}(\mathrm{a})$-associated $\mathrm{Lp}-\mathrm{PLA}_{2}$ activity might have influenced the plasma levels of this enzyme in ERA patients since the mean serum levels of $L p(a)$ in our patients as well as in controls are between 8.6 and $11.2 \mathrm{mg} / \mathrm{dl}$ - according to our previously published results, the plasma levels as well as the distribution of Lp-PLA ${ }_{2}$ between LDL and HDL can be influenced by the presence of $L p(a)$ only when plasma levels of this lipoprotein exceed $30 \mathrm{mg} / \mathrm{dl}$ [33].

An important observation of the present study is that ERA patients exhibited higher autoantibody titers against all types of mildly oxLDL (oxLDL $L_{L}$, oxLDL $L_{P}$ and oxLDL $_{D}$ ) at baseline compared with controls. One year of therapy with DMARDs resulted in a significant decrease of autoantibody titers against all types of oxLDL compared with the respective baseline values, a finding that could be attributed, at least partially, to the repression of the immune system activation due to immunointervention. Importantly, the antibody titers against $\operatorname{oxLDL}_{D}$ are independently associated with ERA, thus providing evidence that such types of mildly oxLDL may be implicated in the pathophysiology of ERA. Indeed, previously published results showed that modified LDL with characteristics of minimally modified LDL, but not extensively oxidized LDL, is present in the synovial fluid of patients with rheumatoid arthritis [36].

Another important finding of the present study is that ERA patients exhibit low plasma HDL-cholesterol levels at baseline. According to our previously published results, this phenomenon could be at least partially attributed to the increased activity of the cholesterol ester transferring protein observed in plasma of ERA patients [23]. The present study further shows

Table 4

Multivariate logistic regression analysis of factors associated with the presence of early rheumatoid arthritis

\begin{tabular}{llc}
\hline & Odds ratio & $95 \%$ confidence interval $(\beta)$ \\
\hline Antibodies against oxidized low-density lipoprotein in the lag phase & 0.431 & $0.023-7.945$ \\
Antibodies against oxidized low-density lipoprotein in the propagation phase & 0.155 & $0.010-2.295$ \\
Antibodies against oxidized low-density lipoprotein in the decomposition phase & 0.047 & $0.008-0.282$ \\
Plasma lipoprotein phospholipase $\mathrm{A}_{2}$ activity & 1.044 & $1.013-1.077$ \\
\hline
\end{tabular}

The model includes antibodies against oxidized low-density lipoprotein in the lag phase, the propagation phase and the decomposition phase, and plasma lipoprotein phospholipase $A_{2}$ activity as defined from univariate analysis after adjustment for age and female gender. 
that HDL-cholesterol levels are inversely correlated with autoantibody titers against oxLDL $L_{P}$ and $\operatorname{oxLDL}_{D}$. Furthermore, autoantibody titers against $\operatorname{oxLDL}_{D}$ at baseline are inversely correlated with HDL-Lp-PLA ${ }_{2}$. Several studies over the past years have demonstrated that HDL exerts potent anti-inflammatory, antioxidant and antiatherogenic effects through its constituents. Among these constituents, the enzyme Lp-PLA ${ }_{2}$ may have a prominent role by degrading proinflammatory oxidized phospholipids formed on LDL during oxidation, thus limiting their accumulation on oxLDL [13]. The negative correlation between HDL-Lp-PLA ${ }_{2}$ activity and antibodies against oxLDL $L_{D}$ found in the present study could therefore be attributed to the fact that oxLDL $L_{D}$ compared with the other types of oxLDL is enriched in oxidized phospholipids that significantly contribute to the antigenicity of this type of oxLDL [37]. These phospholipids are substrates for HDL-Lp-PLA ${ }_{2}$; consequently the HDL-Lp-PLA ${ }_{2}$ activity could significantly lower the levels of oxidized phospholipids formed on oxLDL $L_{D}$, thus diminishing the antigenicity of this type of oxLDL. In addition to the HDL-Lp-PLA ${ }_{2}$, the Apo A-I content of HDL can bind oxidized lipids and remove them from LDL, therefore significantly contributing to the HDL-mediated retardation of LDL oxidation and thus the prevention of oxLDL proinflammatory activities [38].

According to our results, the low baseline levels of HDL-cholesterol and HDL-Lp-PLA ${ }_{2}$ activity in ERA patients are significantly increased after immunointervention, a phenomenon that could be at least partially attributed to the immunointerventioninduced reduction in cholesterol ester transferring protein activity [23]. The elevation of HDL-cholesterol and HDL-Lp$\mathrm{PLA}_{2}$ activity in ERA patients after immunointervention is associated with a reduction in the autoantibody titers against oxLDL. We may consequently suggest that the immunointervention-induced reduction in the autoantibody titers against oxLDL could be attributed not only to the repression of the immune system activation, but also to the increase in plasma HDL-cholesterol and HDL-Lp-PLA ${ }_{2}$ levels. Furthermore, this action of DMARDs may represent a potentially antiatherogenic effect of these drugs.

\section{Conclusion}

The present study shows for the first time that ERA patients exhibit low plasma Lp-PLA ${ }_{2}$ and HDL- Lp-PLA ${ }_{2}$ activities and elevated autoantibody titers against mildly oxLDL. The low plasma $\mathrm{Lp}-\mathrm{PLA} \mathrm{A}_{2}$ activity and the increased titers against $\mathrm{oxLDL}_{\mathrm{D}}$ are independently associated with ERA, suggesting an important role of these parameters in the pathophysiology of ERA. This hypothesis needs to be further supported by large-scale clinical studies.

\section{Competing interests}

The authors declare that they have no competing interests.

\section{Authors' contributions}

ESL wrote the paper and performed the biochemical measurements. ANG participated in the selection of the patients and therapy. ECP contributed to the biochemical measurements and to writing the paper. AIP participated in the statistical analysis and in writing the paper. AAD participated in the selection of the patients and therapy. ADT conceived the idea for the study, participated in its design and coordination, and helped to draft the manuscript. All authors read and approved the final manuscript.

\section{Acknowledgements}

This study was supported by a grant from the General Secretariat of Research and Technology (PENED 2001, ED 375 program). ESL and ECP were recipients of fellowships from this program.

\section{References}

1. Haugeberg G, Orstavik RE, Kvien TK: Effects of rheumatoid arthritis on bone. Curr Opin Rheumato/ 2003, 15:469-475.

2. Gabriel SE, Crowson CS, Kremers HM, Doran MF, Turesson C, O'Fallon WM, Matteson EL: Survival in rheumatoid arthritis: a population-based analysis of trends over $\mathbf{4 0}$ years. Arthritis Rheum 2003, 48:54-58.

3. Symmons DP: Looking back: rheumatoid arthritis - aetiology, occurrence and mortality. Rheumatology 2005, 44:iv14-iv17.

4. Goodson N: Coronary artery disease and rheumatoid arthritis. Curr Opin Rheumatol 2002, 14:115-120.

5. Van Doornum S, McColl G, Wicks I: Accelerated atherosclerosis: an extraarticular feature of rheumatoid arthritis? Arthritis Rheum 2002, 46:862-873.

6. Steinberg D, Parthasarathy S, Carew TE, Khoo JC, Witztum JL: Beyond cholesterol. Modifications of low-density lipoprotein that increase its atherogenicity. N Engl J Med 1989, 320:915-924.

7. Bhakdi S, Lackner KJ, Han SR, Torzewski M, Husmann M: Beyond cholesterol: the enigma of atherosclerosis revisited. Thromb Haemost 2004, 91:639-645.

8. Holvoet $P$, Collen D: Oxidation of low density lipoproteins in the pathogenesis of atherosclerosis. Atherosclerosis 1998, 137:S33-S38.

9. Shaw P: Rethinking oxidized low-density lipoprotein, its role in atherogenesis and the immune responses associated with it. Arch Immunol Ther Exp (Warsz) 2004, 52:225-239.

10. Dai L, Lamb DJ, Leake DS, Kus ML, Jones HW, Morris CJ, Winyard PG: Evidence for oxidised low density lipoprotein in synovial fluid from rheumatoid arthritis patients. Free Radic Res 2000, 32:479-486.

11. McMahon M, Grossman J, FitzGerald J, Dahlin-Lee E, Wallace DJ, Thong BY, Badsha H, Kalunian K, Charles C, Navab M, et al.: Proinflammatory high-density lipoprotein as a biomarker for atherosclerosis in patients with systemic lupus erythematosus and rheumatoid arthritis. Arthritis Rheum 2006, 54:2541-2549.

12. Esterbauer $\mathrm{H}$, Gebicki J, Puhl H, Jurgens G: The role of lipid peroxidation and antioxidants in oxidative modification of LDL. Free Radic Biol Med 1992, 13:341-390.

13. Tselepis AD, Chapman JM: Inflammation, bioactive lipids and atherosclerosis: potential roles of a lipoprotein-associated phospholipase $A_{2}$, platelet activating factor-acetylhydrolase. Atheroscler Supp/ 2002, 3:57-68.

14. Karabina S-A, Bairaktari E, Tzallas C, Siamopoulos K, Tselepis A: Increased activity of platelet-activating factor acetylhydrolase in low-density lipoprotein subfractions induces enhanced lysophosphatidylcholine production during oxidation in patients with heterozygous familial hypercholesterolaemia. Eur J Clin Invest 1997, 27:595-602.

15. Tselepis AD, Dentan C, Karabina SA, Chapman MJ, Ninio E: PAFdegrading acetylhydrolase is preferentially associated with dense LDL and VHDL-1 in human plasma. Catalytic characteristics and relation to the monocyte-derived enzyme. Arterioscler Thromb Vasc Biol 1995, 15:1764-1773. 
16. Packard CJ, O'Reilly DS, Caslake MJ, McMahon AD, Ford I, Cooney J, Macphee CH, Suckling KE, Krishna M, Wilkinson FE, et al:: West of Scotland Coronary Prevention Study Group. Lipoprotein-associated phospholipase $A_{2}$ as an independent predictor of coronary heart disease. N Engl J Med 2000, 343:1148-1155

17. Ballantyne CM, Hoogeveen RC, Bang $H$, Coresh J, Folsom AR, Heiss G, Sharrett AR: Lipoprotein-associated phospholipase A2, high-sensitivity $C$-reactive protein, and risk for incident coronary heart disease in middle-aged men and women in the Atherosclerosis Risk in Communities (ARIC) study. Circulation 2004, 109:837-842.

18. Fukumoto $M$, Shoji $T$, Emoto $M$, Kawagishi T, Okuno $Y$, Nishizawa $Y$ : Antibodies against oxidized LDL and carotid artery intimamedia thickness in a healthy population. Arterioscler Thromb Vasc Biol 2000, 20:703-707.

19. Lourida ES, Papathanasiou Al, Goudevenos JA, Tselepis AD: The low-density lipoprotein (LDL)-associated PAF-acetylhydrolase activity and the extent of LDL oxidation are important determinants of the autoantibody titers against oxidized LDL in patients with coronary artery disease. Prostaglandins Leukot Essent Fatty Acids 2006, 75:117-126.

20. Tsouli SG, Kiortsis DN, Lourida ES, Xydis V, Tsironis LD, Argyropoulou MI, Elisaf M, Tselepis AD: Autoantibody titers against OxLDL are correlated with Achilles tendon thickness in patients with familial hypercholesterolemia. J Lipid Res 2006, 47:2208-2214.

21. Papathanasiou AI, Lourida ES, Tsironis LD, Goudevenos JA, Tselepis AD: Short- and long-term elevation of autoantibody titers against oxidized LDL in patients with acute coronary syndromes Role of the lipoprotein-associated phospholipase $A(2)$ and the effect of atorvastatin treatment. Atherosclerosis 2006 in press.

22. Arnett FC, Edworthy SM, Bloch DA, McShane DJ, Fries JF, Cooper NS, Healey LA, Kaplan SR, Liang MH, Luthra HS, et al.: The American Rheumatism Association 1987 revised criteria for the classification of rheumatoid arthritis. Arthritis Rheum 1988, 31:315-324.

23. Georgiadis AN, Papavasiliou EC, Lourida ES, Alamanos Y, Kostara $C$, Tselepis AD, Drosos AA: Atherogenic lipid profile is a feature characteristic of patients with early rheumatoid arthritis: effect of early treatment - a prospective, controlled study. Arthritis Res Ther 2006, 8:R82.

24. Prevoo ML, van 't Hof MA, Kuper $\mathrm{HH}$, van Leeuwen MA, van de Putte LB, van Riel PL: Modified disease activity scores that include twenty-eight-joint counts. Development and validation in a prospective longitudinal study of patients with rheumatoid arthritis. Arthritis Rheum 1995, 38:44-48.

25. Felson DT, Anderson JJ, Boers M, Bombardier C, Furst D, Goldsmith C, Katz LM, Lightfoot R Jr, Paulus H, Strand Vm, et al:: American College of Rheumatology. Preliminary definition of improvement in rheumatoid arthritis. Arthritis Rheum 1995, 38:727-735.

26. Liapikos TA, Antonopoulou S, Karabina S, Tsoukatos DC, Demopoulos CA, Tselepis A: Platelet-activating factor formation during oxidative modification of low-density lipoprotein when PAF-acetylhydrolase has been inactivated. Biochem Biophys Acta 1994, 1212:353-360.

27. Tsimihodimos V, Karabina SA, Tambaki AP, Bairaktari E, Miltiadous G, Goudevenos JA, Cariolou MA, Chapman MJ, Tselepis AD, Elisaf $\mathrm{M}$ : Altered distribution of platelet-activating factor-acetylhydrolase activity between LDL and HDL as a function of the severity of hypercholesterolemia. J Lipid Res 2002, 43:256-263.

28. Tsimihodimos V, Karabina S-A, Tambaki AP, Bairaktari E, Goudevenos J, Chapman J, Elisaf M, Tselepis A: Atorvastatin preferentially reduces LDL-associated platelet-activating factor acetylhydrolase activity in dyslipidemias of type IIA and type IIB. Arterioscler Thromb Vasc Biol 2002, 22:306-311.

29. Friedewald WT, Levy RI, Fredrickson DS: Estimation of the concentration of low-density lipoprotein cholesterol in plasma, without use of the preparative ultracentrifuge. Clin $\mathrm{Chem}$ 1972, 18:499-502

30. Tselepis A, Elisaf M, Besis S, Karabina S-A, Chapman M, Siamopoulou A: Association of the inflammatory state in active juvenile rheumatoid arthritis with hypo-high-density lipoproteinemia and reduced lipoprotein-associated platelet-activat- ing factor acetylhydrolase activity. Arthritis Rheum 1999, 42:373-383.

31. Stafforini DM, Elstad MR, Mclntyre TM, Zimmerman GA, Prescott SM: Human macrophages secrete platelet-activating factor acetylhydrolase. J Biol Chem 1990, 265:9682-9687.

32. Tjoelker LW, Stafforini DM: Platelet-activating factor acetylhydrolase in health and disease. Biochim Biophys Acta 2000 , 1488:102-123.

33. Karabina SA, Elisaf MC, Goudevenos J, Siamopoulos KC, Sideris $\mathrm{D}$, Tselepis AD: PAF-acetylhydrolase activity of $\operatorname{Lp}(a)$ before and during $\mathrm{Cu}(2+)$-induced oxidative modification in vitro. Atherosclerosis 1996, 125:121-134.

34. Blencowe C, Hermetter A, Kostner GM, Deigner HP: Enhanced association of platelet-activating factor acetylhydrolase with lipoprotein (a) in comparison with low density lipoprotein. $J$ Biol Chem 1995, 270:31151-31157.

35. Tsimikas S, Brilakis ES, Miller ER, McConnell JP, Lennon RJ, Kornman KS, Witztum JL, Berger PB: Oxidized phospholipids, Lp(a) lipoprotein, and coronary artery disease. N Engl J Med 2005, 353:46-57.

36. Dai L, Zhang Z, Winyard P, Gaffney K, Jones H, Blake D, Morris C: A modified form of low-density lipoprotein with increased electronegative charge is present in rheumatoid arthritis synovial fluid. Free Radic Biol Med 1997, 22:705-710.

37. Lourida ES, Papathanasiou AI, Goudevenos JA, Tselepis AD: The low-density lipoprotein (LDL)-associated PAF-acetylhydrolase activity and the extent of LDL oxidation are important determinants of the autoantibody titers against oxidized LDL in patients with coronary artery disease. Prostaglandins Leukot Essent Fatty Acids 2006, 75:117-126.

38. Ansell B, Navab M, Watson K, Fonarow G, Fogelman A: Antiinflammatory properties of HDL. Rev Endocr Metabl Disorder 2004, 5:351-358 